\title{
Oil Film Stiffness of Double Involute Gears Based on Thermal EHL Theory
}

\author{
Zhaoming Yin, Zhimin Fan ${ }^{*}$ and Feng Jiang
}

\begin{abstract}
Lubrication failure is one of the main failure forms of gear failure. Time varying meshing stiffness is an important factor affecting the dynamic behavior of gears. However, the influence of oil film stiffness is usually ignored in the research process. In this paper, according to the meshing characteristics of double involute gears, based on the non-Newtonian thermal EHL theory, a new calculation method of normal and tangential oil film stiffness for double involute gears is established by the idea of subsection method. The oil film stiffness difference between double involute gears and common involute gears is analyzed, and the influence of tooth waist order parameters, working conditions, and thermal effect on the oil film stiffness are studied. The results reveal that there are some differences between normal and tangential oil film stiffness between double involute gears and common involute gears, but there is little difference. Compared with the torque, rotation speed and initial viscosity of the lubricating oil, the tooth waist order parameters have less influence on the oil film stiffness. Thermal effect has a certain influence on normal and tangential oil film stiffness, which indicates that the influence of thermal effect on the oil film can not be ignored. This research proposes a calculation method of normal and tangential oil film stiffness suitable for double involute gears, which provides a theoretical basis for improving the stability of the transmission.
\end{abstract}

Keywords: Double involute gear (DIG), Elastohydrodynamic lubrication (EHL), Oil film stiffness, Thermal effect

\section{Introduction}

Gear transmission is one of the most extensive transmission forms in the field of mechanical transmission. In the gear transmission system, the stiffness has a significant influence on the dynamic performance and reliability of the gear transmission. Lubricating oil widely exists between the meshing tooth surfaces, and forms a lubricating film with normal bearing capacity and low tangential shear strength between friction surfaces, which is the important basis for gear lubrication performance, lubrication state judgment and lubrication failure [1, 2]. Under the actual working condition, the whole meshing stiffness of the gear system is composed of the contact stiffness of the meshing tooth surface and the oil film stiffness, which has important influence on the vibration, noise and the

\footnotetext{
*Correspondence: zmfan@163.com

College of Electromechanical Engineering, Qingdao University of Science \& Technology, Qingdao 266061, China
}

fatigue life of the gears [3]. In the traditional dynamic model of the gears, the contact stiffness caused by bending deformation, shear deformation and elastic deformation of tooth surface is usually considered, while the oil film stiffness caused by viscoelastic deformation of the oil film is ignored $[4,5]$. However, relevant research shows that under the condition of EHL, the oil film stiffness produced by the viscoelastic deformation of the oil film can reach or even exceed the magnitude of the contact stiffness [6], and has a great effect on the overall stiffness and dynamic characteristics of the gear, so the influence of oil film stiffness cannot be ignored.

In the study of the oil film stiffness, Li et al. [7] and Zhao [8] deduced the empirical formulas of oil film normal stiffness in contact area according to the empirical formulas of minimum and central film thickness, respectively. Hagiu et al. [9] deduced the approximate calculation of the oil film normal stiffness in contact area of high-speed ball bearing considering thermal effect and 
lack of oil by using the empirical formula of minimum film thickness. Although these empirical formulas can describe the relationship between load and the oil film stiffness, it only represent the variation of the oil film stiffness at a certain engagement position in the contact area, and the distribution of oil film stiffness in the whole contact area cannot be accurately obtained [10]. Moreover, the oil film is squeezed seriously at the minimum position of the film thickness, and the deformation of the thickness is small, the calculated results of the oil film stiffness are larger [11, 12]. Qin et al. [13] established the calculation model of oil film normal stiffness based on the EHL theory, and studied the change of oil film stiffness with load, equivalent radius of curvature and entrainment velocity. Zhang et al. [14] compared and analyzed the oil film normal stiffness with empirical formula method and numerical method respectively, and studied the influence of working conditions, regular roughness and oil supply state on the oil film stiffness. Li et al. [15] considered the distribution of the oil film and the pressure characteristic of the contact regions, set up the oil film stiffness calculation model based on the EHL theory, and compared with the experiment. Zhou et al. $[16,17]$ established a calculation model of normal and tangential oil film stiffness of the spur gear, but without considering the influence of temperature.

With the development of gear transmission towards high load carrying capacity, high speed, and high precision, etc., the effects of EHL characteristics of the oil film between the teeth surfaces on gear drive have attracted widespread attention, and the non-Newtonian characteristics of fluids, thermal effects, and roughness have gradually been introduced into oil film EHL research. Liu et al. [18] analyzed the TEHL problem of a finite line contact by using a multilevel method. Yang et al. [19] approximated the instantaneous thermal EHL of the meshing pair of helical gears by the thermal EHL of two tapered rollers in opposite orientation, and researched the effect of different parameters on the thermal EHL characteristics. Shi et al. [20] established a dynamic-meshing model with mixed EHL for spur gears. He et al. [21] presented a MEHL model for finite roller-coated half space interfaces, and studied the influence of roughness on the lubrication of rollers. These researches prove that the oil film between the meshing tooth surfaces under high shear force and frictional shear between rough peaks under mixed EHL will generate a large amount of heat, reduce the viscosity of the lubricating oil, and have a greater impact on the deformation of the oil film. Based on this, Chen et al. [6] proposed a calculation model for oil film normal stiffness based on the point contact EHL theory, considering the effects of heat, lubricating oil speed, and oil film distribution. In view of the dynamic change of the oil film stiffness during the normal operation of rolling bearings is difficult to be accurately reflected by the traditional empirical formula, Lei et al. [22] established an oil film stiffness model based on multi- parameter coupling, taking into account the non-Newtonian fluid, rough surface morphology, thermal effect, time-dependent effect and other factors. Zhang [11, 14] studied the influence of rough surface on the oil film normal stiffness of spur gears.

During the actual meshing transmission process of gears, the state of force and motion is more complex. Under the action of tooth surface extrusion, the oil film will be extruded along the thickness direction, resulting in oil film normal stiffness. At the same time, there is a relative sliding speed between the meshing tooth surfaces, resulting in shear deformation and oil film tangential stiffness. From the above researches that with the development of EHL theory, the study of the oil film stiffness has attracted extensive attention, but still in infancy. Time-varying meshing stiffness is an important factor in the dynamic response of gears, but in the study of gear dynamics, most of them only consider the meshing stiffness of gears, and the oil film stiffness is ignored. Even if the influence of oil film stiffness is considered, most of them only limited to normal direction, the research on oil film tangential stiffness is neglected [23, 24], and most of them do not consider the influence of thermal effect. In addition, the shearing force produced by the relative sliding between the meshing tooth surfaces makes the oil film temperature rise, while the high-pressure compression also causes the lubricating oil heat up. The rise of the oil film temperature will cause the change of its viscosity, thus changing the thickness of the oil film and affecting the lubrication condition, and relevant research shows that thermal effect is an important factor affecting the meshing performance, scuffing bearing capacity, contact, and bending performance of the gear system [25]. So the influence of thermal effect cannot be neglected in the research of the oil film.

The double involute gear is a new type of gear that combines the advantages of the involute gear and the double arc gear, its tooth profile is composed of two involute curves, and connected by a transition curve [26, 27], as shown in Figure 1. Relevant researches have proved that this kind of gear has good manufacturability and dynamic characteristics of the involute gear, and has high bearing capacity simultaneously $[28,29]$. As graded near the pitch point, the roots are thickened, the tops are thinned, and the contact lines passing through the graded position of the tooth waist are interrupted. Therefore, there are some differences in lubrication characteristics between double involute gears (DIG) and common involute gears (CIG), and the existing calculation methods of oil film stiffness 


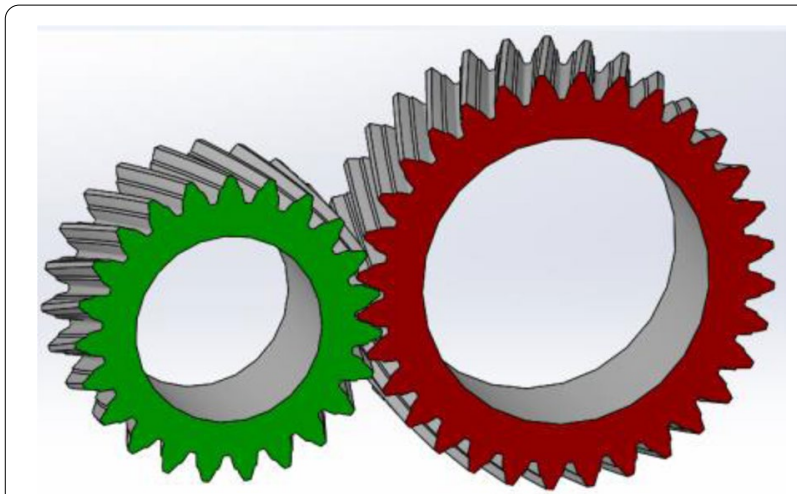

Figure 1 Double involute gear transmission

are not suitable for double involute gears. Based on this, a new calculation method of normal and tangential oil film stiffness of double involute gears is established by the idea of subsection method in non-Newtonian TEHL status. Afterward, comparative analysis the difference of the oil film stiffness distribution between double involute gears and common involute gears. In order to explore the evolution rule of the oil film stiffness of double involute gears, the influence of the tooth waist order parameters, working conditions, and thermal effect on the oil film stiffness of double involute gears were to studied, which has important theoretic and practical meaning.

\section{Meshing Characteristics of Double Involute Gears}

\subsection{Geometric Analysis}

Figure 2 shows the basic tooth profile of double involute gears [28], where $l_{a}{ }^{*}$ and $l_{\mathrm{d}}{ }^{*}$ are the tooth waist altitude coefficients of the tooth top and root, respectively. $y_{a}$ " and $y_{\mathrm{d}}$ " are the tooth waist tangential modification coefficients of the tooth top and root, respectively. Other parameters can be found in Ref. [30]. $l_{a}{ }^{*}, l_{\mathrm{d}}{ }^{*}, y_{a}$ ", and $y_{\mathrm{d}}{ }^{*}$ are the main characteristics of double involute gears different from common involute gears, and these characteristics are also the core research on double involute gears. For ease of calculation, $l_{a}^{*}=l_{d}^{*}=l^{*}$, and $y_{a}^{*}=y_{d}^{*}=y^{*}$ are chosen in this paper. Figure 3 is contact area diagram of double involute gear pair. In the figure, $N_{1} N_{1}^{\prime} N_{2} N_{2}^{\prime}$ is the theoretical meshing plane, $B_{1} B_{1}^{\prime} B_{2} B_{2}^{\prime}$ is the actual engagement plane, $B_{1}$ and $B_{2}$ are the inlet and outlet points on transverse, respectively. When the contact line passes through the graded position of the tooth waist, the relative sliding speed and tooth surface friction force of the double involute gear pair will reverse, and the double involute gear must be made into a helical gear to ensure a continuous and smooth meshing drive.

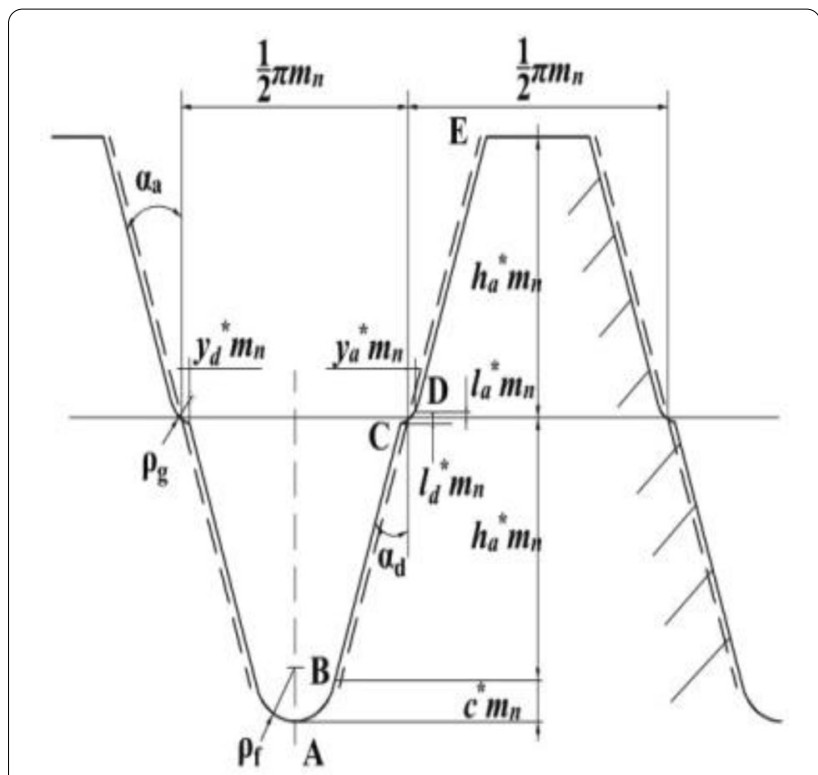

Figure 2 Basic tooth profile of double involute gears

\subsection{Calculation of Basic Parameters}

The variation of a contact line during the process of a meshing tooth pair from the start of meshing to the disengagement is shown in Figure 4(a), the contact lines passing through the graded position of the tooth waist can be shown in Figure 4(b). In the figure, the displacement difference between two contact lines across the graded position of the tooth waist is $\Delta l$, and $\Delta l=\left(y_{a}^{*}+y_{d}^{*}\right) m_{n}-\left(l_{a}^{*}+l_{d}^{*}\right) m_{n} \tan \alpha_{a}$. The length of

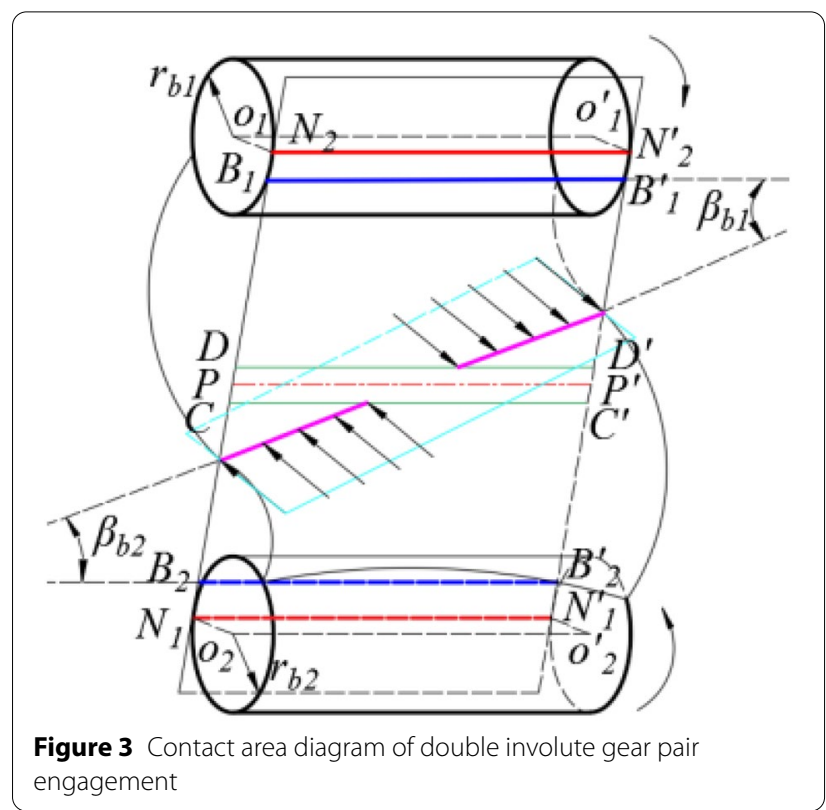




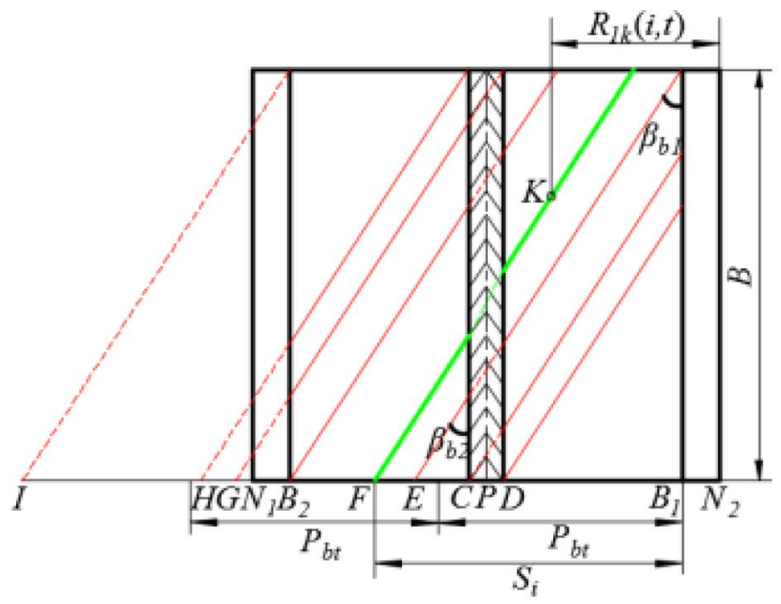

(a)

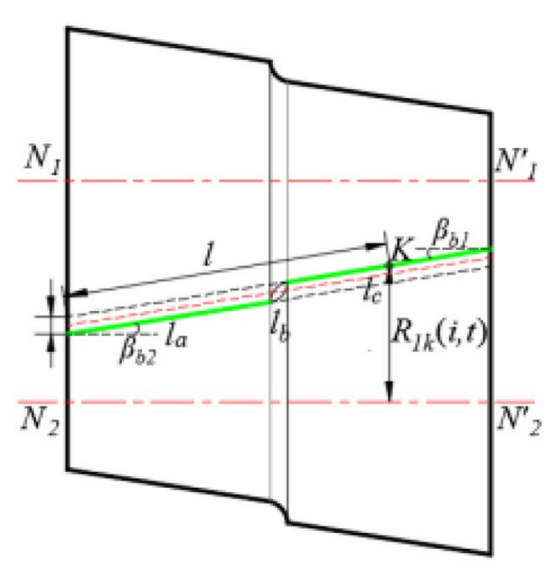

(b)

Figure 4 Contact line expansion on base cylinder when $\varepsilon_{a}>\varepsilon_{\beta}$

contact line at different meshing time can be expressed as follows:
The equivalent curvature radius of the driven gear at point $K$ can be expressed as follows:

$$
l_{c}^{i}(t)=\left\{\begin{array}{l}
r_{b 1} \omega_{1} t / \sin \beta_{b}, 0 \leq t \leq t_{B_{1} D}, \\
l_{B_{1} D} / \sin \beta_{b}, t_{B_{1} D}<t \leq t_{B_{1} C} \\
\left(r_{b 1} \omega_{1} t-l_{C D}\right) / \sin \beta_{b}, t_{B_{1} C} C t \leq t_{B_{1} E}, \\
\left(B \tan \beta_{b}-\Delta l-l_{C D}\right) / \sin \beta_{b}, t_{B_{1} E}<t \leq t_{B_{1} B_{2}}, \\
\left(l_{B_{1} D}+l_{B_{2} C}+B \tan \beta_{b}-r_{b 1} \omega_{1} t-\Delta l\right) / \sin \beta_{b}, t_{B_{1} B_{2}}<t \leq t_{B_{1} G}, \\
l_{B_{2} C} / \sin \beta_{b}, t_{B_{1} G}<t \leq t_{B_{1} H}, \\
\left(l_{B_{1} B_{2}}+B \tan \beta_{b}-r_{b 1} \omega_{1} t\right) / \sin \beta_{b}, t_{B_{1} H}<t \leq t_{B_{1} I} .
\end{array}\right.
$$

The equivalent curvature radius of the driving pinion at point $K$ is shown as follows:

$$
R_{1 K}(t)=\left\{\begin{array}{l}
N_{2} B_{1}+r_{b 1} \omega_{1} t+\Delta l-l \sin \beta_{b}, 0 \leq t \leq t_{B_{1} D}, \\
\left\{\begin{array}{l}
0,\left(0 \leq l \leq l_{a}\right), \\
N a N,\left(l_{a}<l \leq l_{a}+l_{b}\right), \\
N_{2} B_{1}+r_{b 1} \omega_{1} t+\Delta l-l \sin \beta_{b},\left(l_{a}+l_{b}<l \leq l_{a}+l_{b}+l_{c}\right),
\end{array} t_{B_{1} D<t \leq t_{B_{1} C},}, \quad \begin{array}{l}
N_{2} B_{1}+r_{b 1} \omega_{1} t-l \sin \beta_{b},\left(0 \leq l \leq l_{a}\right), \\
N a N,\left(l_{a}<l \leq l_{a}+l_{b}\right), \\
N_{2} B_{1}+r_{b 1} \omega_{1} t+\Delta l-l \sin \beta_{b},\left(l_{a}+l_{b}<l \leq l_{a}+l_{b}+l_{c}\right),
\end{array}\right. \\
\left\{\begin{array}{l}
N_{B_{1}} B_{1}+r_{b 1} \omega_{1} t-l \sin \beta_{b},\left(0 \leq l \leq l_{a}\right), t_{B_{1} G}<t \leq t_{B_{1} H}, \\
N a N,\left(l_{a}<l \leq l_{a}+l_{b}+l_{c}\right),
\end{array}\right. \\
N_{2} B_{1}+r_{b 1} \omega_{1} t-l \sin \beta_{b}, t_{B_{1} H}<t \leq t_{B_{1} I} .
\end{array}\right.
$$




$$
R_{2 K}(t)=N_{1} N_{2}-R_{1 K}(t) .
$$

The effective curvature radius, relative sliding speed, entrainment speed and slide-roll ratio at the meshing point $\mathrm{K}$ can be defined as follows:

$$
\left\{\begin{array}{l}
R_{K}=\frac{R_{1 K}(t) R_{2 K}(t)}{R_{1 K}(t)+R_{2 K}(t)}, \\
u_{S K}=\left|\omega_{1} R_{1 K}(t)-\omega_{2} R_{2 K}(t)\right|, \\
u_{r K}=\frac{\omega_{1} R_{1 K}(t)+\omega_{2} R_{2 K}(t)}{2}, \\
\xi=u_{S K} / u_{r K} .
\end{array}\right.
$$

The detailed calculation of relevant parameters in the above formulas can be found in Ref. [31].

The working load of gear transmission is time-varying and non-linear. In one meshing cycle, the friction status of the same meshing position on the tooth surface at different meshing moments and the friction status of different meshing positions at the same moment are different [32]. In addition, the double involute gear is graded near the pitch point, the contact lines passing through this position is discontinuous, and there exists a dislocation difference between the contact line of the top and root meshing zones. Therefore, this article uses the "subsection method" to study the lubrication characteristics of double involute gear transmission and the oil film stiffness between the meshing tooth surfaces. As shown in Figure 5, the master-slave control is widely employed in the robot manipulation. In most cases, the joystick or the keyboard is the routine input device for the robot master-slave control system. The system presented in this paper is shown in Figure 1. Assume that there are $n$ pairs of gears simultaneously engaged at a certain meshing time $t$, that is, there are $n$ contact lines in the meshing tooth surfaces, and then each contact line is divided into $\mathrm{m}$ equal parts. The contact line length of the $j$ th segment on the $i$ th contact line at time $t$ is:

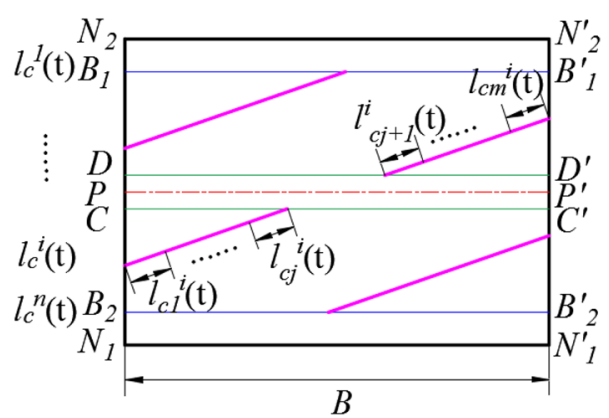

Figure 5 Contact line division schematic diagram of double involute gear pair engagement

$$
l_{c j}^{i}(t)=\frac{l_{c}^{i}(t)}{m},(i=1,2, \cdots, n, j=1,2, \cdots, m) .
$$

After segmented treatment, the length of each contact line is very short, so the contact of each pair of double involute gears can be approximately equivalent to the contact of a finite number of thin spur gears. Assuming that the load is uniformly distributed along the contact line direction, the load on the $j$ th segment of the $i$ th contact line at time $t$ is:

$$
F_{j}^{i}(t)=\frac{T_{p}}{r_{b 1}} \frac{l_{c}^{i}(t)}{m L_{z}(t)},
$$

where $L z(t)$ is the total length of all contact lines in the action plane at time $t$.

\section{Governing Equations and Models}

\subsection{Thermal EHL Equations}

The generalized Reynolds equation associated with nonNewtonian and thermal effect in line contact is [33]

$$
\frac{\partial}{\partial x}\left[\left(\frac{\rho}{\eta}\right)_{e} h^{3} \frac{\partial p}{\partial x}\right]=12 u_{r} \frac{\partial}{\partial x}\left(\rho^{*} h\right) .
$$

The definitions of equivalent symbols in the above formula are as follows:

$$
\begin{aligned}
& (\rho / \eta)_{e}=12\left(\eta_{e} \rho_{e}^{\prime} / \eta_{e}^{\prime}-\rho_{e}^{\prime \prime}\right), \quad \rho^{*}=2\left(\rho_{e}-\eta_{e} \rho_{e}^{\prime}\right), \\
& \rho_{e}=(1 / h) \int_{0}^{h} \rho \mathrm{d} z, \quad \rho_{e}^{\prime}=\left(1 / h^{2}\right) \int_{0}^{h} \rho \int_{0}^{z}(1 / \eta) \mathrm{d} z^{\prime} \mathrm{d} z, \\
& \rho_{e}^{\prime \prime}=\left(1 / h^{3}\right) \int_{0}^{h} \rho \int_{0}^{z}\left(z^{\prime} / \eta\right) \mathrm{d} z^{\prime} \mathrm{d} z, \\
& \eta_{e}=h / \int_{0}^{h}(1 / \eta) \mathrm{d} z, \quad \eta_{e}^{\prime}=h^{2} / \int_{0}^{h}(z / \eta) \mathrm{d} z .
\end{aligned}
$$

The boundary conditions can be expressed as [34]:

$$
\left\{\begin{array}{c}
x=x_{\text {in }}, p\left(x_{\text {in }}\right)=0, \\
x=x_{\text {out }}, p\left(x_{\text {out }}\right)=\partial p / \partial x=0,
\end{array}\right.
$$

where $x_{i n}, x_{\text {out }}$ are the boundary coordinates of the engaging-in and engaging-out of the meshing area, respectively. The equation of the film thickness is:

$$
h=h_{0}+\frac{x^{2}}{2 R}-v(x),
$$


where $h_{0}$ denotes the spacing between two rigid contact bodies, $v(x)$ is the total elastic deflection of two contact bodies, and can be shown as:

$$
v(x)=\frac{2}{\pi E^{\prime}} \int_{x_{\text {in }}}^{x_{\text {out }}} p(s) \ln (s-x)^{2} \mathrm{~d} s .
$$

The equation reflecting the relationship between viscosity, pressure and temperature is [35]
The temperature of two gears and oil film should be continuous on the two interfaces, and should meet the continuous condition of the interface heat flow, the equations are given by

$$
\left\{\begin{array}{l}
\left.k \frac{\partial T}{\partial z}\right|_{z=0}=\left.k_{1} \frac{\partial T}{\partial z_{a}}\right|_{z_{a}=0} \\
\left.k \frac{\partial T}{\partial z}\right|_{z=h}=\left.k_{2} \frac{\partial T}{\partial z_{b}}\right|_{z_{b}=0}
\end{array}\right.
$$

$$
\eta=\eta_{0} \exp \left\{\left(\ln \eta_{0}+9.67\right)\left[\left(1+p / p_{0}\right)^{z_{0}}\left(\frac{T-138}{T_{0}-138}\right)^{-1.1}-1\right]\right\}
$$

where $z_{0}$ is the Reynolds viscosity-pressure coefficient, $z_{0}=\alpha /\left[5.1 \times 10^{-9}\left(\ln \eta_{0}+9067\right)\right] . T_{0}$ denotes the ambient temperature, $T_{0}=313 \mathrm{~K} . \eta_{0}$ is the initial oil film viscosity, and $T$ is the temperature of the oil film.

The Ree-Eyring fluid equivalent viscosity $\eta^{*}$ is introduced by

$$
\eta^{*}=\eta \frac{\tau / \tau_{0}}{\sinh \left(\tau / \tau_{0}\right)},
$$

where $\tau_{0}$ is the characteristic shear stress, and the shear stress $\tau$ can be expressed as [36]:

$$
\tau=\tau_{a}+z \frac{\partial p}{\partial x},
$$

where $\tau_{a}$ represents the shear stress of pinion teeth surfaces, and $z$ denotes the coordinate across the film thickness.

The equation reflecting the relationship between fluid density, pressure and temperature is [37]

$$
\begin{aligned}
\rho= & \rho_{0}\left[1+0.6 \times 10^{-9} p /\left(1+1.7 \times 10^{-9} p\right)\right. \\
& \left.-0.00065\left(T-T_{0}\right)\right],
\end{aligned}
$$

where $\rho_{0}$ is the initial fluid density. [19]

The fluid energy equation is expressed as follows

$$
\begin{aligned}
& c_{f}\left[\rho u \frac{\partial T}{\partial x}-\left(\frac{\partial}{\partial x} \int_{0}^{z} \rho u \mathrm{~d} z^{\prime}\right) \frac{\partial T}{\partial z}\right] \\
& =k_{f} \frac{\partial^{2} T}{\partial z^{2}}-\frac{T}{\rho} \frac{\partial \rho}{\partial T}\left(u \frac{\partial p}{\partial x}\right)+\eta^{*}\left(\frac{\partial u}{\partial z}\right)^{2} .
\end{aligned}
$$

The solid energy equations are shown as:

$$
\left\{\begin{array}{l}
c_{a} \rho_{a} u_{a} \frac{\partial T}{\partial x}=k_{a} \frac{\partial^{2} T}{\partial z_{a}^{2}}, \\
c_{b} \rho_{b} u_{b} \frac{\partial T}{\partial x}=k_{b} \frac{\partial^{2} T}{\partial z_{b}^{2}},
\end{array}\right.
$$

where $c_{i}, \rho_{i}, u_{i}$ and $k_{i}$ are specific heat capacity, density, line speed, and thermal conductivities of two gear materials $a$ and $b(i=a, b)$. where $\left.T\right|_{z_{a}=-d}=T_{0},\left.T\right|_{z_{b}=d}=T_{0}$ are the temperature boundary conditions along $z_{a}$ and $z_{b}$ directions, in which $d$ is the thickness of the thermal layers.

The load balance equation is:

$$
w=\int_{x_{\text {in }}}^{x_{\text {out }}} p(x) \mathrm{d} x
$$

where $w$ represents the load per unit contact length.

\subsection{Stiffness Models of the Oil Film}

The value of stiffness is expressed as the ratio of the force to the deformation. During the process of gear meshing transmission, with the rotation of the gear, the meshing position of the gear pair is constantly changing, the load and deformation of the gear pair are also constantly changing. At the same time, it also affects the oil film stiffness between the meshing tooth surfaces.

Based on the definition of stiffness, the normal oil film stiffness can be expressed as the ratio of the increment of the normal force $\Delta F_{n}$ to the oil film compression

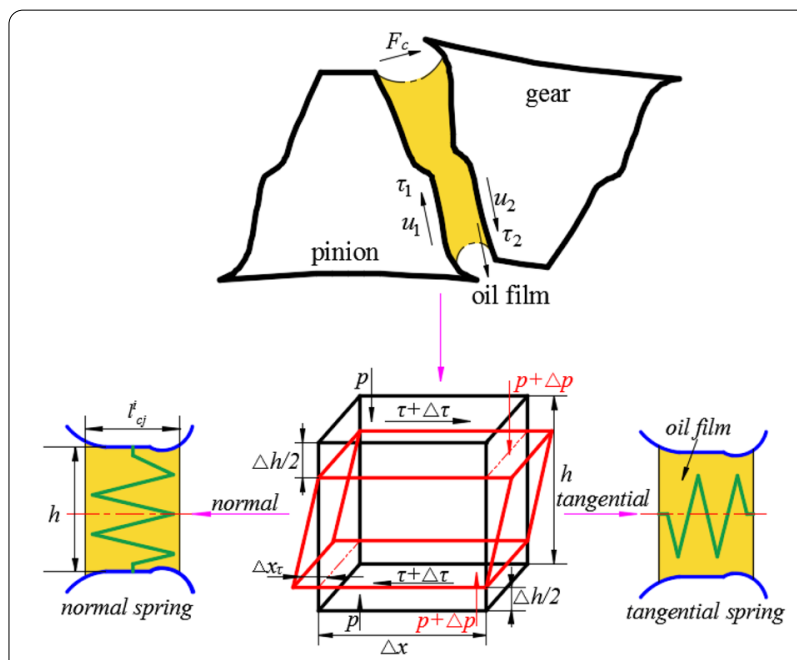

Figure 6 Oil film stiffness models of double involute gears 
deformation $\Delta h$. Lubricating oil film has remarkable viscoelastic properties, under the pressure load, the oil film will produce compression deformation along the thickness direction, and forms the oil film normal stiffness. The load of the oil film is different in different meshing position, and the deformation along the film thickness direction is also different. In order to obtain the accurate calculation model of the oil film normal stiffness suitable for double involute gears, the oil film between each pair of thin spur gear pairs is equivalent to a pair of massless spring, as shown in Figure 6, and the stiffness of these massless springs is numerically superposed to obtain the oil film normal stiffness of double involute gears. The specific calculation formula is expressed as:

$$
k_{n}(t)=\frac{\Delta F_{n}(t)}{\Delta h(t)}=\frac{\sum_{i=1}^{n} \sum_{j=1}^{m} l_{c j}^{i}(t) \Delta p_{c j}^{i}(x, t)}{\frac{1}{n} \frac{1}{m} \sum_{i=1}^{n} \sum_{j=1}^{m} \Delta h_{c j}^{i}(x, t)},
$$

where $\Delta p$ denotes the pressure difference as the normal increment of force.

The oil film tangential stiffness can be expressed as the ratio between the increment of tangential force $\Delta F_{\tau}$ and its increased tangential deformation $\Delta x_{\tau}$. During the meshing transmission process, the double involute gears have a relative sliding between the meshing tooth surfaces, so that the oil film between the meshing tooth faces is subjected to the tangential force, thereby the tangential deformation occurs, and forms the oil film tangential stiffness. In order to obtain the variation of the oil film tangential stiffness, the oil film between a pair of thin spur gear pairs can also taken as a massless spring along tangential direction, as shown in Figure 6. In the whole calculation domain, the specific calculation formula for tangential stiffness can be expressed as:

$$
k_{\tau}(t)=\frac{\Delta F_{\tau}(t)}{\Delta x_{\tau}(t)}=\frac{\sum_{i=1}^{n} \sum_{j=1}^{m} l_{c j}^{i}(t) \Delta \tau_{c j}^{i}(x, z, t)}{\frac{1}{n} \frac{1}{m} \sum_{i=1}^{n} \sum_{j=1}^{m} \Delta \gamma_{c j}^{i}(x, z, t) h_{c j}^{i}(x, z, t)},
$$

where $\gamma$ is the shear strain of the current oil film, $\gamma=\int_{0}^{t_{1}} \dot{\gamma} \mathrm{d} t . \dot{\gamma}$ is the shear rate, and $\dot{\gamma}=\partial u / \partial z . t_{1}$ is the time of the oil film across the contact zone.

\section{Results and Discussion}

During the process of numerical calculation, in order to reduce the number of variables in the equations, and increase the universality of the solution, it is necessary to treat the equations mentioned above into dimensionless.
$\mathrm{X}=x / b, P=p / p_{H}, \bar{W}=w /\left(E^{\prime} R\right), \bar{U}=\eta_{\mathrm{o}} u_{r} /\left(E^{\prime} R\right), \bar{\rho}=\rho / \rho_{\mathrm{o}}, \bar{u}$ $=u / u_{\mathrm{r}}, \bar{\eta}=\eta / \eta_{0}, \bar{\eta}^{*}=\eta^{*} / \eta_{0}, \bar{T}=T / T_{0}, \bar{\tau}=\tau / p_{\mathrm{H}}, \bar{\tau}_{0}=\tau_{0} / p_{H}$, $H=h / h_{R}, Z=z R / b^{2}$

Based on the geometric parameters of double involute gears, the load, equivalent radius curvature, slide-roll ratio and other parameters of different meshing positions are obtained (as shown in Figure 8), and then brought them into the TEHL model. In the process of calculation the TEHL equations, taking the ambient temperature as the initial value, the generalized Reynolds equation is used to solve the pressure, and its results will be substituted into the energy and heat conduction equations to solve the temperature field. The obtained temperature and pressure are taken as the next instantaneous initial value, and it is substituted into the model to solve, and alternately cycles until the accuracy requirements are

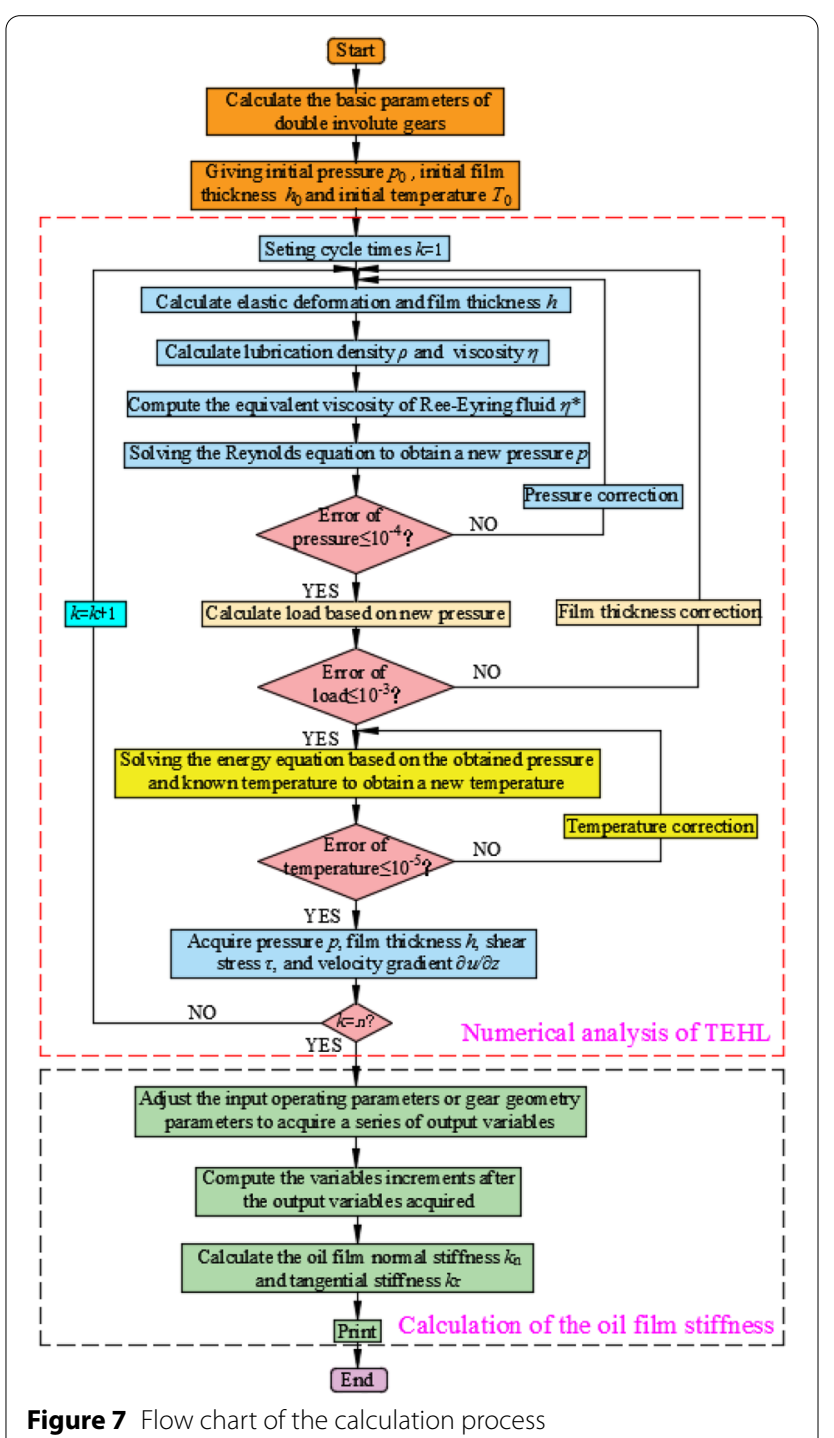


Table 1 Geometric, operating parameters of double involute gears and performance of lubricating oil

\begin{tabular}{ll}
\hline Parameter & Value \\
\hline Number of teeth & $23 / 32$ \\
Normal modulus $m_{n}(\mathrm{~mm})$ & 3 \\
Normal pressure angle $a_{n}\left({ }^{\circ}\right)$ & 20 \\
Tooth width $B(\mathrm{~mm})$ & 50 \\
Helical angle $\beta\left(^{\circ}\right)$ & $16^{\circ} 57^{\prime} 42^{\prime \prime}$ \\
Specific heat capacity $(\mathrm{J} / \mathrm{kg} \cdot \mathrm{K})$ & $\mathrm{C}_{a}=c_{b}=460$ \\
Modulus of elasticity $(\mathrm{GPa})$ & $E_{a}=E_{b}=210$ \\
Density $\left(\mathrm{kg} / \mathrm{m}^{3}\right)$ & $\rho_{a}=\rho_{b}=7850$ \\
Input torque $T_{\mathrm{p}}(\mathrm{N} \cdot \mathrm{m})$ & 160 \\
Rotating speed of pinion $n_{1}(\mathrm{r} / \mathrm{min})$ & 2000 \\
Thermal conductivity of fluid $k_{f}(\mathrm{~W} /(\mathrm{m} \cdot \mathrm{K}))$ & 0.14 \\
Density of fluid $\rho_{\mathrm{f}}\left(\mathrm{kg} / \mathrm{m}^{3}\right)$ & 860 \\
Specific heat of lubricant $c_{f}(\mathrm{~J} / \mathrm{kg} \cdot \mathrm{K})$ & 2290 \\
Lubricant ambient temperature $T_{0}(\mathrm{~K})$ & 313 \\
Initial viscosity of lubricant $\eta_{0}(\mathrm{~Pa} \cdot \mathrm{s})$ & 0.08 \\
Viscosity-temperature coefficient $\beta_{f}\left(\mathrm{~K}^{-1}\right)$ & 0.04 \\
Eyring stress $\tau_{0}(\mathrm{MPa})$ & $1.2 \times 10^{7}$ \\
\hline
\end{tabular}

met. The lubrication parameters obtained from the thermoelastohydrodynamic lubrication equations are substituted into the oil film stiffness calculation model, the normal and tangential oil film stiffness of double involute gears are obtained, and Figure 7 shows the flow chart of the computational procedure. In the process of solution, the multilevel method is used for pressure iteration, the multilevel multi-integration method is used for the elastic deformation, and the energy equations is solved by a sequential column sweeping technique. Five layers of grids are used for calculation, and the finest layer along
$X$ direction has 961 nodes. The calculating domain for the line contact is $X=[-4.0,1.6]$. There are 21 nodes employed for solving the energy equations in $Z$ direction, and 12 nodes in both surfaces 1 and 2 . The input parameters for lubricating oil and a double involute gear drive are depicted in Table 1.

To verify the accuracy of the oil film stiffness calculation model established in this paper, the oil film normal stiffness $\left(k_{\mathrm{hm}}\right.$ and $\left.k_{\mathrm{nc}}\right)$ obtained by Dowson-Higginson minimum and central film thickness empirical formulas [10], and the normal and tangential oil film stiffness calculation methods proposed by Xiao [38] are selected for comparative analysis under the same working conditions. Figure 8(a) shows the change of normal oil film stiffness with load obtained by different calculation models. It predicts that with increasing the load, the oil film normal stiffness obtained by the four calculation models gradually increases. The value of the oil film normal stiffness obtained by the model proposed in this paper is between $k_{\mathrm{hm}}$ and $k_{\mathrm{nc}}$, and there is not much difference with Xiao's calculation result. Figure 8(b) shows the change trend of the oil film tangential stiffness obtained by two models is the same, and the difference of the two results is small. From the comparative analysis mentioned above, the oil film stiffness calculated by the model proposed in this paper is in good consistent with the results of relevant empirical formulas and methods, which can prove the accuracy of the model.

\subsection{Numerical Solution of Basic Parameters and Lubrication Characteristics}

As graded near the pitch points of double involute gears, the load along the transverse and the contact line of a pair are different from that of common involute gears [39]. As

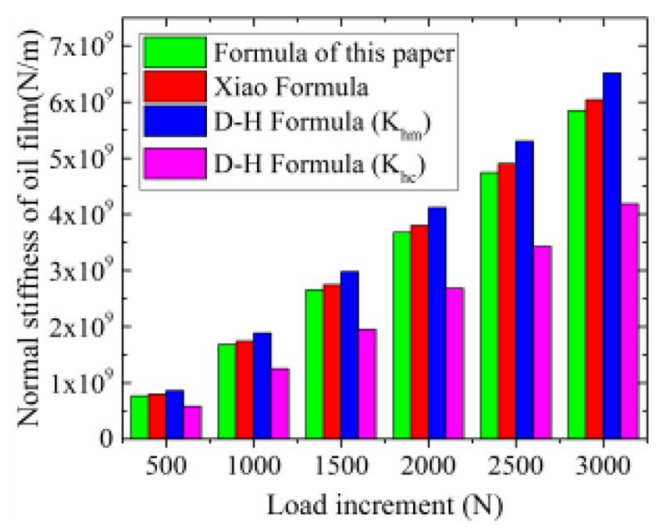

(a)

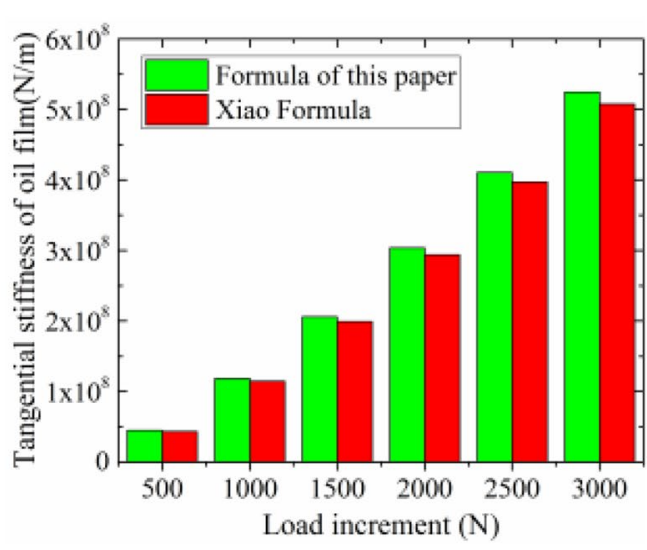

(b)

Figure 8 Comparison of oil film stiffness under different calculation models 


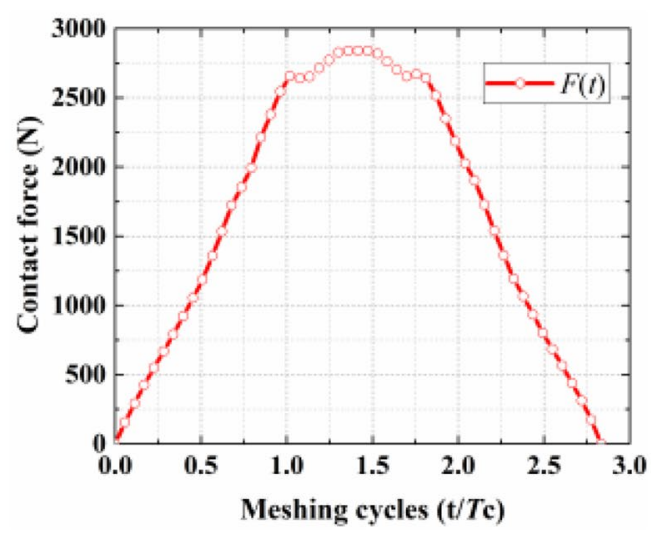

(a)

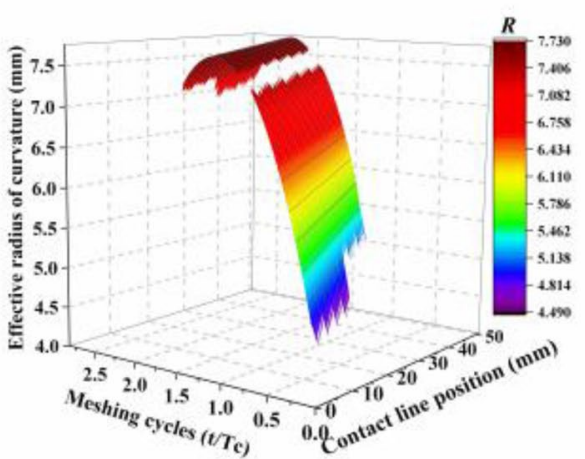

(c)

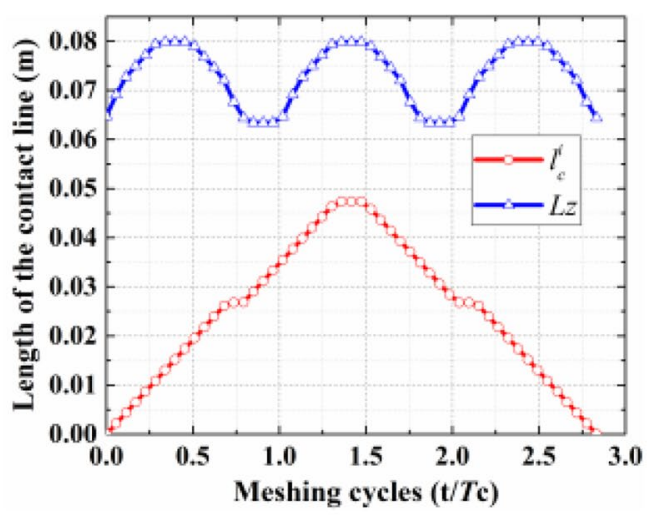

(b)

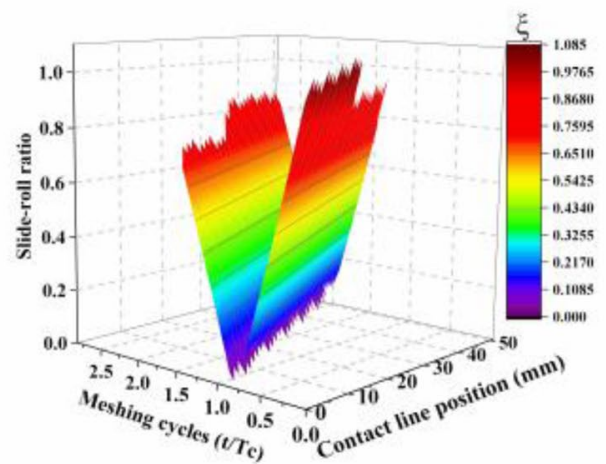

(d)

Figure 9 Contact force, length of contact line, equivalent radius of curvature, and slide-roll ratio of double involute gears

shown in Figure 9(a) and (b), the contact force and the contact line length remains the same for a time during the process of increase and decrease, and the total length of contact lines has periodic variation. In Figure 9(c), the effective curvature radius of double involute gears gradually increases and then decreases, and its value in the initial engagement zone is smaller than that in the exit engagement zone. In Figure 9(d), the slide-roll ratio of double involute gears goes through a process of decrease gradually, reaches the minimal near the pitch point, and then increase slowly.

Figure 10(a) and (b) shows the distribution of the lubrication pressure and thickness, respectively. From the figures, we can find that the lubricating pressure in the initial engagement region is significantly higher than that in the exit region, while the distribution of the film thickness is just opposite to its lubricating pressure, and the oil film thickness is larger in the exit region. Figure 10(c) presents the distribution of the oil film temperature rise. From the figure we can find that the temperature rise of the oil film is smaller near the tooth waist grading position, and the farther away from the tooth waist grading position is, the greater the temperature rise is. The oil film temperature rise at the starting engagement is significantly higher than that at the meshing out engagement. This is due to the fact that the oil film temperature rise is closely related to the slide-roll ratio between the meshing tooth surfaces, the larger the slide-roll ratio is, the greater the internal friction of the oil film, and the higher the oil film temperature rise is. Figure 10 (d) presents the change of shear stress in the whole contact region, the direction of the shear stress changes through the tooth waist grading position, and the shear stress at the starting engagement is larger. 


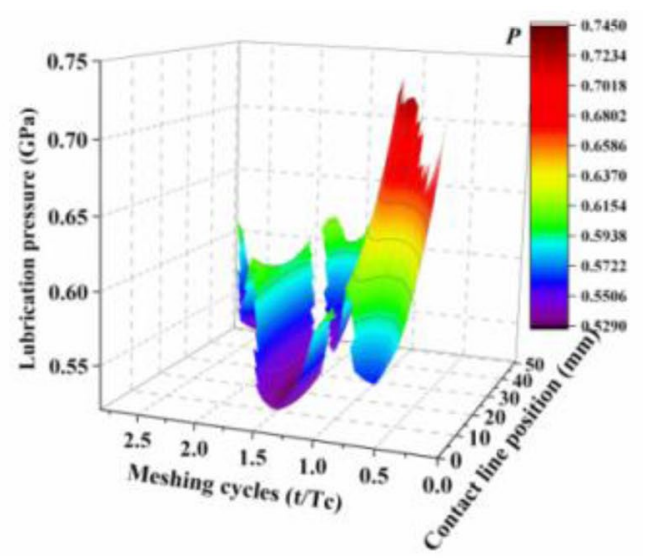

(a)

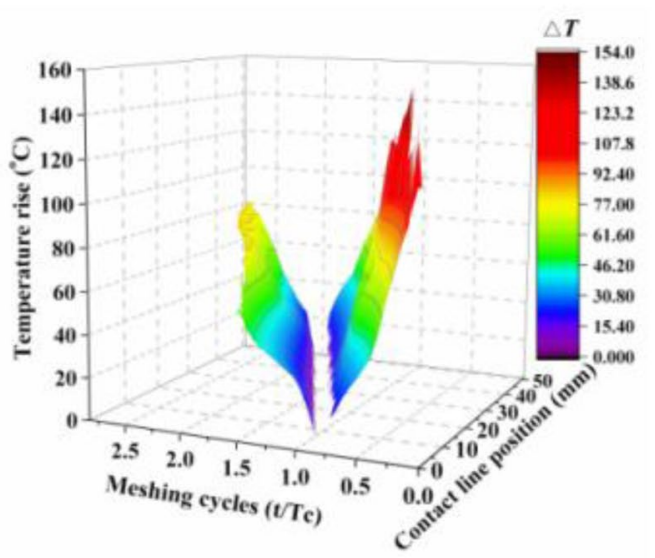

(c)

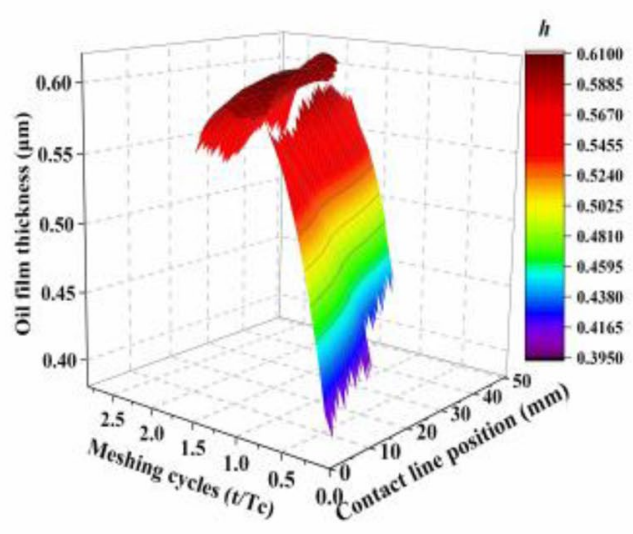

(b)

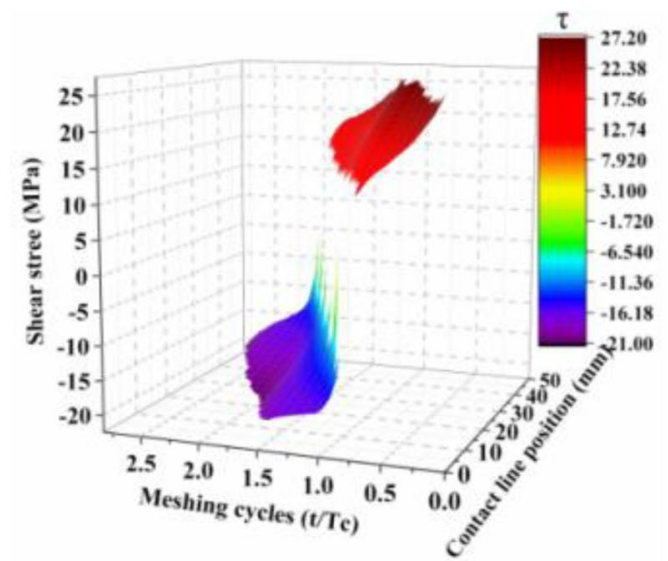

(d)

Figure 10 Lubrication characteristics of double involute gears

\subsection{Comparison of the Oil Film Stiffness between Double Involute Gears and Common Involute Gears}

Figure 11 presents the comparison of the oil film stiffness of a single pair of teeth during the whole process from meshing in to meshing out between double involute gears and common involute gears. The figure shows that the oil film stiffness distribution of double involute gears is similar to that of common involute gears, but there are some differences in the value. As the double involute gear does not contact at the tooth waist position, the oil film stiffness of double involute gears has obvious discontinuity at this position. The oil film normal stiffness of the two kinds of gears is significantly higher than that of the oil film tangential stiffness, the normal and tangential oil film stiffness near the pitch point position of the two kinds of gears are higher than that of the other meshing regions. The comparison shows that the maximum normal and tangential oil film stiffness of the double involute gear are both smaller than that of common involute gears, while the minimum oil film normal stiffness is larger than that of common involute gears, which shows that the impact resistance of double involute gears near the tooth waist is higher than that of the common involute gear, as smaller oil film stiffness is conducive to improve the impact resistance of the contact body [38]. Meanwhile, in the whole contact region, the oil film stiffness of double involute gears have no obvious mutation, which shows that the transmission stability of the double involute gear is better.

\subsection{Influence of the Tooth Waist Order Parameters}

Figure 12 presents the change of the oil film stiffness with the tooth waist order parameters. As shown in Figure 12(a), in the tooth root meshing zone, the oil film normal stiffness increases with increasing $l^{*}$ value, but decreases with increasing $l^{*}$ value in the tooth top 


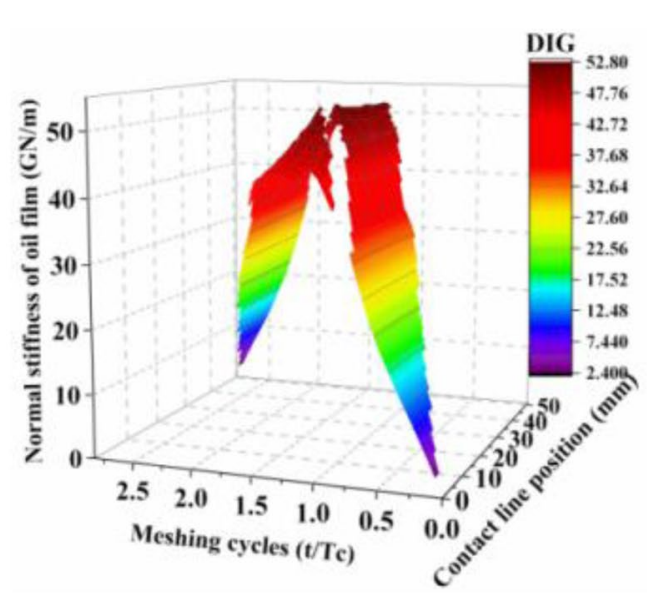

(a)

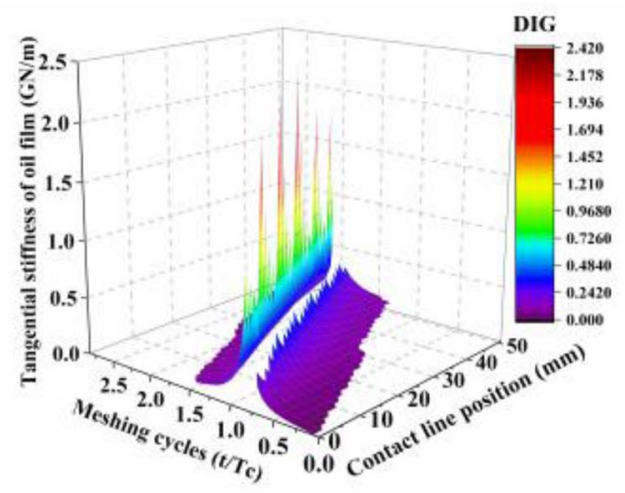

(c)

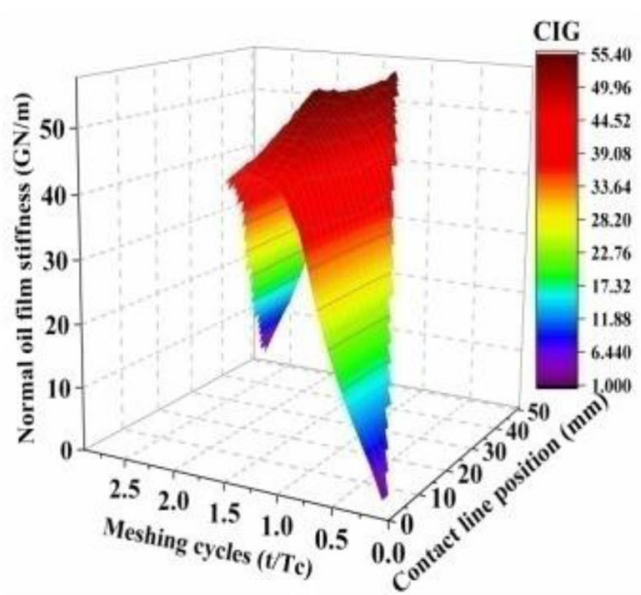

(b)

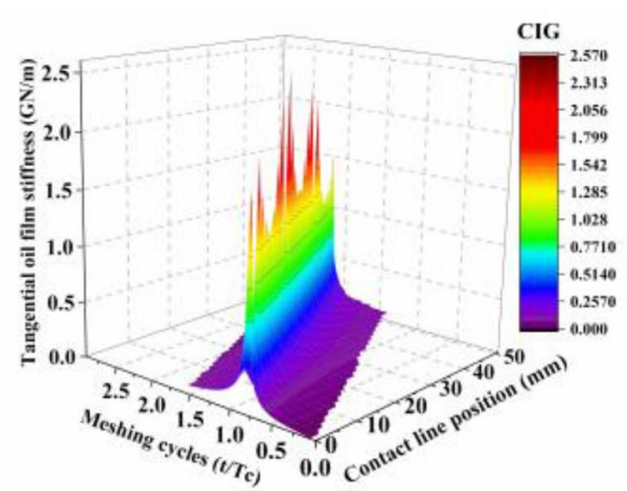

(d)

Figure 11 Comparision of the oil film stiffness between DIG and CIG

meshing zone. Figure 12(b) shows the change of the oil film tangential stiffness with increasing $l^{\prime \prime}$ value. The oil film tangential stiffness has a small increases with increasing $l$ value in the meshing zones of teeth root and top, while near the tooth waist grading position, the oil film tangential stiffness significantly decreases with the increase of $l^{*}$ value. As the tangential stiffness of the oil film increases with decreasing the slide-roll ratio [38], and the slide-roll ratio of double involute gears reaches the minimum value near the tooth waist grading position. The smaller the $l^{*}$ value is, the smaller the graded zone is, and the smaller the minimum value of slide-roll ratio is. Figure 12(c) shows that the normal oil film stiffness has a small increases with increasing $y^{\text {* value. It can }}$ be seen from Figure 12(d) that the variation of $y^{\text {" value }}$ has few influence on the oil film tangential stiffness at the tooth root and tooth top meshing zones. Besides, the oil film tangential stiffness is more sensitive to the variation of $y^{*}$ value near the tooth waist grading position, and with increasing $y^{*}$ value, the oil film tangential stiffness increases significantly.

\subsection{Effect of Working Conditions}

The initial input torque $T_{\mathrm{p}}$ of the double involute gear is $160 \mathrm{~N} \cdot \mathrm{m}$, and the torque is changed to $200 \mathrm{~N} \cdot \mathrm{m}, 240$ $\mathrm{N} \cdot \mathrm{m}, 280 \mathrm{~N} \cdot \mathrm{m}$, and $320 \mathrm{~N} \cdot \mathrm{m}$ to provide applied load increment. Figure 13 shows that the normal and tangential oil film stiffness increase with increasing input torque along the direction of the transverse, but with increasing the torque increment, the increment of the normal and tangential oil film stiffness decreased slightly. This means that, even if the load increment acting on the meshing tooth surface increases infinitely, the normal and tangential oil film stiffness cannot increase infinitely. This is due to the fact that the lubrication oil film has significant viscoelastic characteristic, the lubrication pressure 


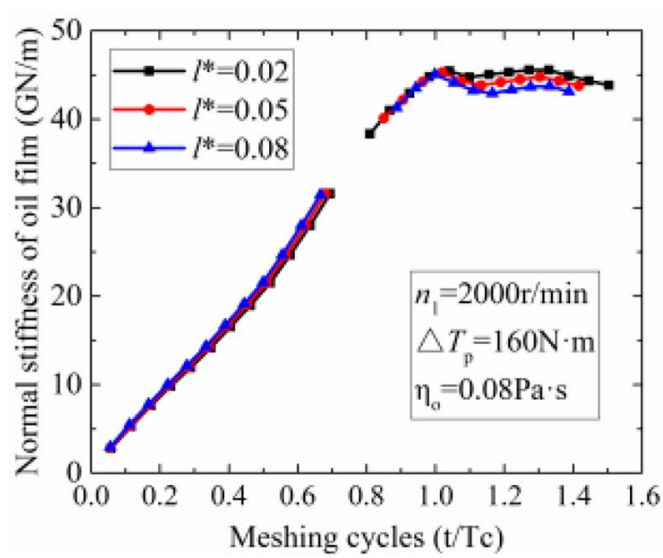

(a)

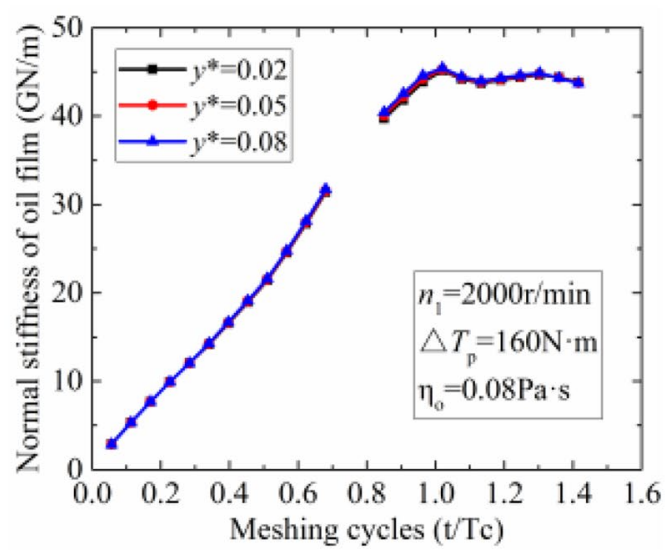

(c)

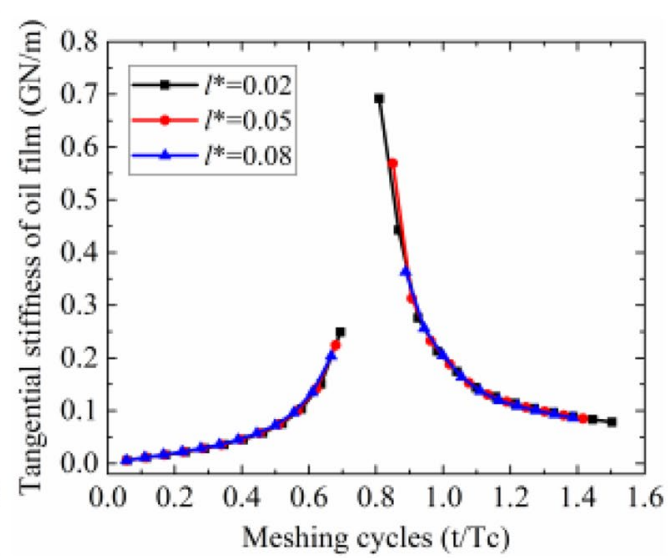

(b)

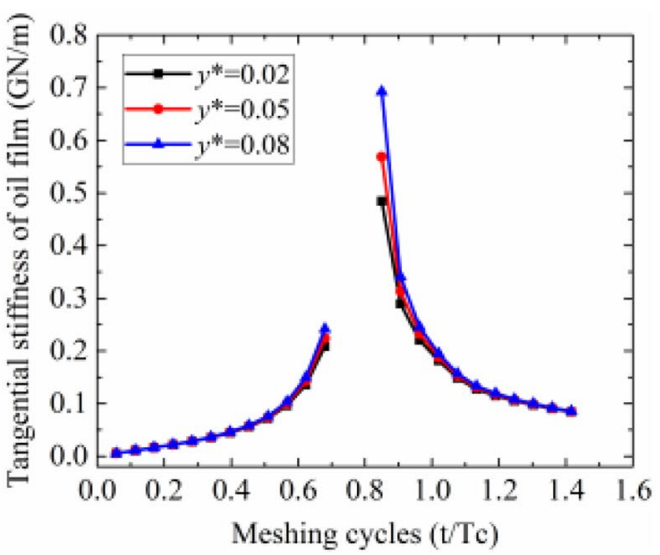

(d)

Figure 12 Influence of tooth waist order parameters on oil film stiffness

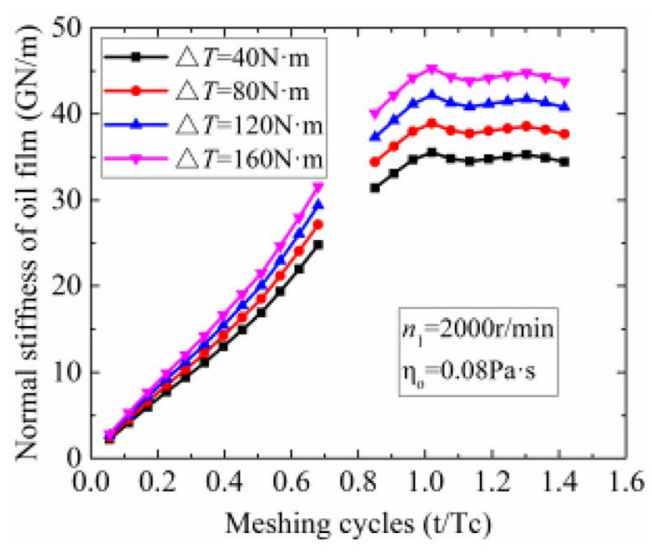

(a)

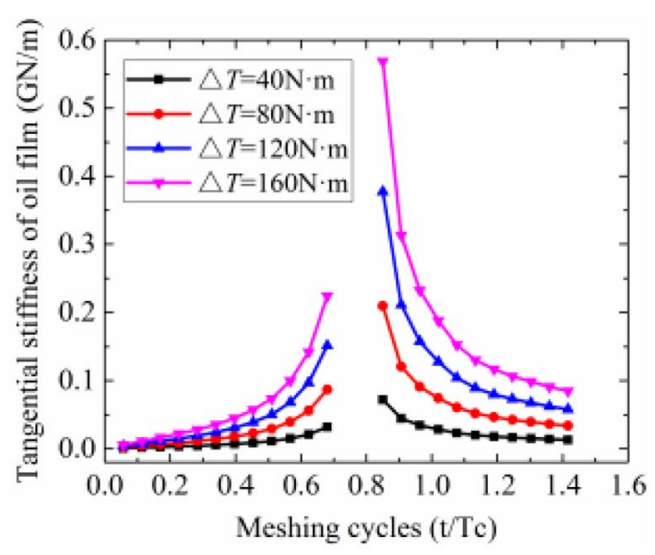

(b)

Figure 13 Influence of the input torque 


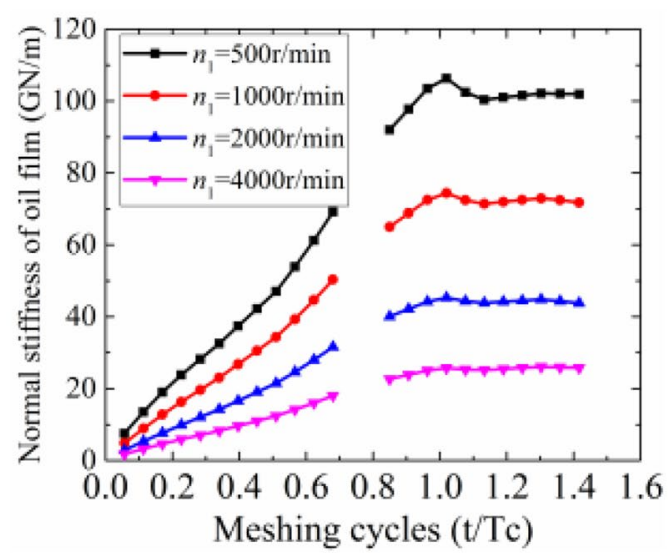

(a)

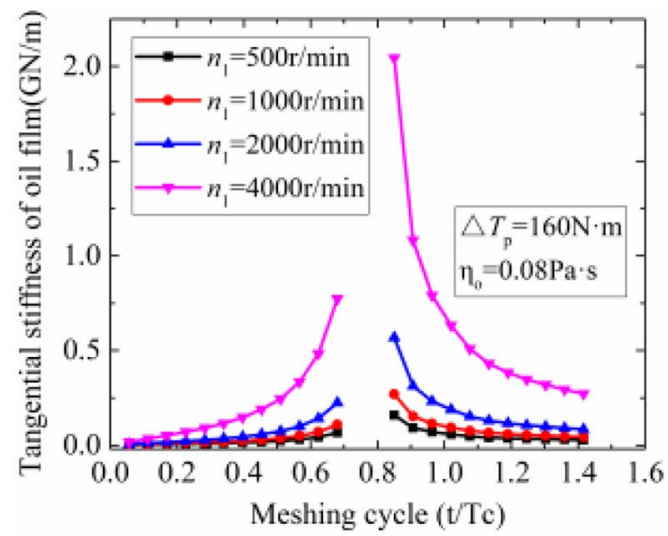

(b)

Figure 14 Influence of the rotation speed

is greatly affected by the load, the input torque increases, the normal load on the oil film increases, thereby increasing the shear stress, and its viscosity increases simultaneously, which makes the deformation of the oil film more difficult. The distribution of the oil film normal stiffness along the transverse is similar with its load distribution, which demonstrate that the applied load has great influence on the distribution of the oil film normal stiffness.

Figure 14 presents the relationship between the oil film stiffness and the rotation speed $n_{1}$ of double involute gears under the same load increment. According to Figure 14(a), with increasing the rotation speed of the double involute gear, the oil film normal stiffness decreases, and the larger the rotation speed is, the smaller the change of the oil film normal stiffness is. This result is due to the increase of the rotation speed, the amount of oil involved in the meshing tooth surface increases, the oil film thickness increases, and the deformation increases under the same load increment, ultimately decreasing the oil film normal stiffness. However, the compression deformation of the oil film becomes more difficult when the thickness of the oil film is increased to a certain extent. Therefore, the change of the oil film normal stiffness of double involute gears is gradually reduced when the rotation speed increased to a certain extent. As shown in Figure 14(b), with increasing the rotational speed, the oil film tangential stiffness of double involute gears increase, and the larger the rotational speed is, the greater the change

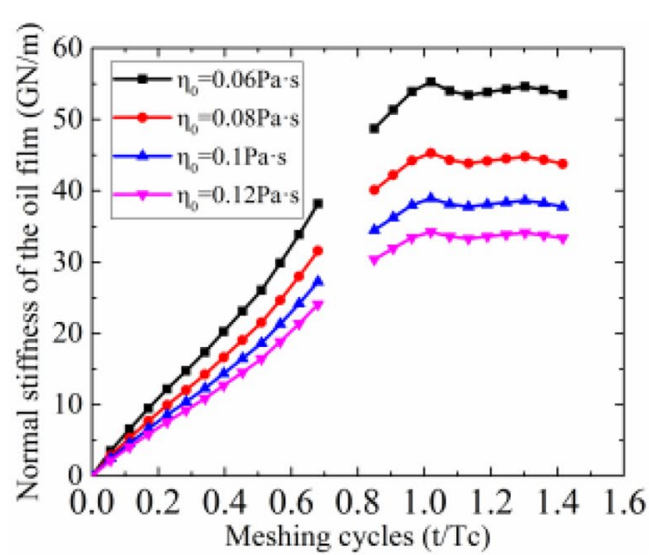

(a)

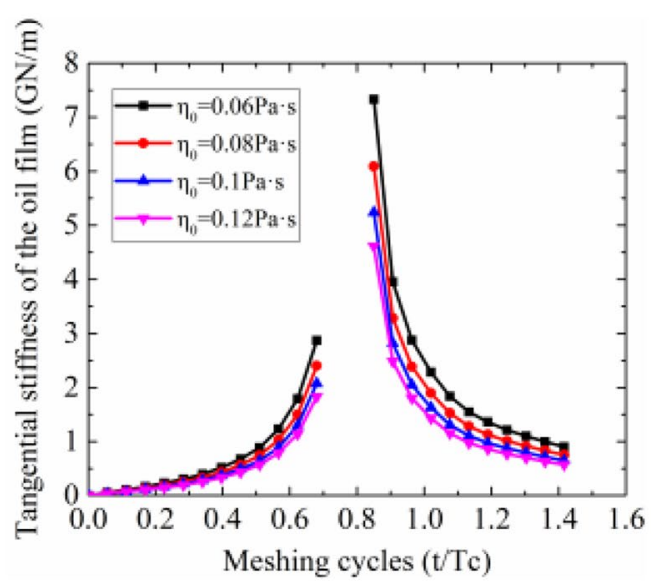

(b)

Figure 15 Influence of the initial lubrication viscosity 
of the oil film tangential stiffness is. This is due to the increase of the rotational speed, the fluidity of the oil film is enhanced, and the integration time of the oil film shear deformation is shortened, finally leading to an decrease of the tangential deformation.

Figure 15 shows the change of the normal and tangential oil film stiffness with initial lubrication viscosity $\eta_{0}$ under the same load increment and rotation speed. It can be seen from the figure that with increasing the initial lubrication viscosity, the normal and tangential oil film stiffness of double involute gears gradually decrease, and the larger the initial lubrication viscosity is, the smaller the reduction of the oil film stiffness is. This is due to the fact that the larger the initial lubrication viscosity is, the greater the thickness of the oil film is. Under the same load increment, the deformation of the oil film along the thickness direction increases, and the oil film normal stiffness decreases. Meanwhile, the increase of the initial lubrication viscosity reduces the fluidity of the oil film, the integral time of the shear deformation of the oil film increases, the tangential deformation increases, and finally lead to the decreases of the oil film tangential stiffness. However, the effect of the lubrication viscosity on the oil film stiffness is the result of two opposite effects [6], with increasing the initial lubrication viscosity, the oil film compression becomes difficult, and the shear stress decrease. Therefore, lead to the reduction of the oil film stiffness decrease with increasing the initial lubrication viscosity.

\subsection{Influence of Thermal Effect}

Compared with isothermal EHL analysis, thermal EHL analysis considers the effect of friction heat and compression heat on the lubrication performance. Thermal effect causes the heat conduction between the oil film and the gear body, resulting in the change of the temperature, viscosity and density of the oil film, and reacts on the oil film pressure to change. Therefore, there must be some differences in the oil film distribution between isothermal solution and thermal solution. In Figure 16(a), the oil film normal stiffness of double involute gears is lower than its value under isothermal condition after considering the thermal effect. This is due to the reality that the viscosity of lubricating oil decreases with the increase of temperature, and the oil film has larger compression deformation along its thickness direction under the same load increment. According to Figure 16(b), the oil film tangential stiffness under thermal effect is significantly higher than that under isothermal condition. This is because the viscosity of lubricating oil decreases, the velocity of oil film increases and the tangential deformation of oil film decreases. In addition, the difference of the oil film stiffness between isothermal solution and thermal solution are both larger near the graded position of tooth waist, which indicates that the greater the load is, the more obvious the influence of thermal effect on the film stiffness is.

\section{Conclusions}

In this study, based on the idea of subsection method and non-Newtonian TEHL theory, a calculation model of normal and tangential oil film stiffness suitable for double involute gears is proposed. The difference of oil film stiffness distribution between double involute gears and common involute gears were compared, the influence of the tooth waist order parameters, operating parameters,

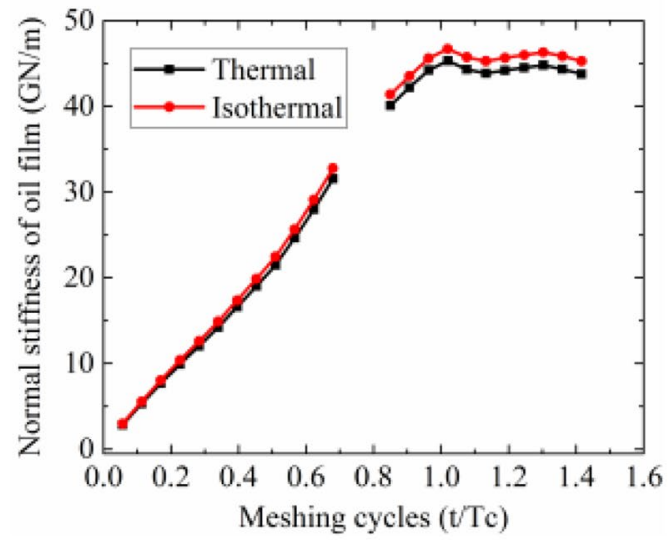

(a)

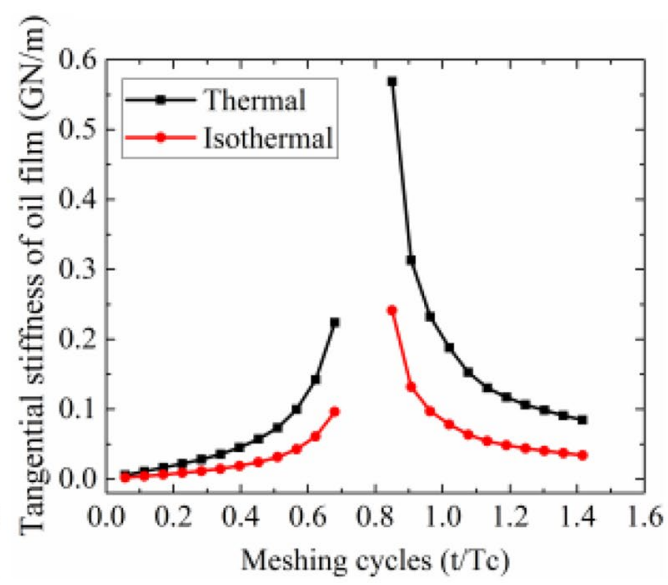

(b)

Figure 16 Oil film stiffness of double involute gears in thermal and isothermal conditions 
and thermal effect on the oil film stiffness were studied. The conclusions are as follows.

(1) The oil film stiffness distribution of double involute gears is similar to that of common involute gears. As the gear waist is not contacted, the oil film stiffness of double involute gears is obviously divided at the position of tooth waist, and the value of oil film stiffness of two kinds of gears is also different. The distribution of the oil film normal stiffness is similar to the applied load, and significantly higher than its tangential stiffness.

(2) The normal and tangential oil film stiffness of double involute gears will be affected by the change of tooth waist order parameters. The tooth waist order parameters have little influence on the oil film normal stiffness, and have significant effect on the oil film tangential stiffness near the tooth waist grading position.

(3) The working parameters of double involute gears have significant influence on its oil film stiffness. The normal and tangential oil film stiffness increase with increasing the input torque. With the increase of the rotation speed, the oil film normal stiffness decrease, and the oil film tangential stiffness increase, especially near the tooth waist grading position.

(4) With increasing the initial viscosity of lubricating oil, the normal and tangential oil film stiffness of double involute gears gradually decrease, and the larger the initial viscosity of lubricating oil is, the smaller the reduction range of oil film stiffness is. Considering the influence of thermal effect, the normal oil film stiffness of double involute gears decreases and the tangential oil film stiffness increases.

\section{Acknowledgements}

Not applicable.

\section{Authors' contributions}

ZF and ZY were in charge of the whole trial; ZY wrote the manuscript; ZY and FJ assisted with sampling and laboratory analyses. All authors read and approved the final manuscript.

\section{Authors' Information}

Zhaoming Yin, born in 1989, is currently a Ph.D. candidate at College of Electromechanical Engineering, Qingdao University of Science \& Technology, China. His research interests include gear transmission.

Zhimin Fan, born in 1963, is currently a professor at College of Electromechanical Engineering, Qingdao University of Science \& Technology, China. He received his PhD degree from Chongaing University, China. His research interests include mechanical transmission and theory.
Feng Jiang, born in 1995, is currently a master candidate at College of Electromechanical Engineering, Qingdao University of Science \& Technology, China. His research interests include gear transmission.

\section{Funding}

Supported by National Natural Science Foundation of China (Grant No. 52075279)

\section{Competing Interests}

The authors declare no competing financial interests.

Received: 9 April 2020 Revised: 19 December 2020 Accepted: 26 May 2021

Published online: 09 June 2021

References

[1] S Z Wen, P Huang, Y Tian, et al. Principles of tribology. Tsinghua University Press, 2018.

[2] GXXie, G Dan, J B Luo. Lubrication under charged conditions. Tribology International, 2015, 84: 22-35.

[3] SY Chen, JYTang, Z Hu. Comparisons of gear dynamic responses with rectangular mesh stiffness and its approximate form. J. Mech. Sci. Technol., 2015, 29(9): 3563-3569.

[4] F Wang, Z D Fang, S J Li. Treatment and contrast verification of meshing stiffness in dynamic model of helical gear. Journal of Vibrication and Shock 2014, 33(6): 13-17.

[5] SY Chen, JY Tang, Y Li, et al. Rotordynamics analysis of a double-helical gear trans-mission system. Meccanica, 2016, 51: 251 -268.

[6] B Chen, J Chen, M L Dong, et al. Modeling method analysis for oil film stiffness calculation based on point contact TEHL theory. Lubrication Engineering, 2013, 38(8): 70-75.

[7] C Li, Z L Sun. Dynamic virtual simulation of deep groove ball bearing: based on elastohydrodynamic lubrication theory. Journal of Aerospace Power, 2009, 24(4):951-956.

[8] L C Zhao. Research on vibration of ball bearing. Hangzhou: Zhejiang University, 2003. (in Chinese)

[9] G D Hagiu, M D Gafitanu. Dynamic characteristics of high speed angular contact ball bearings. Wear, 1997, 211:21-29.

[10] YY Zhang. The study of contact stiffness and damping of an EHL lubrication spur gear pair. Chongqing: Chongqing University, 2016. (in Chinese)

[11] Y Y Zhang, H J Liu, C C Zhu. Oil film stiffness and damping in an elastohydrodynamic lubrication line contact-vibration. Journal of Mechanical Science and Technology, 2016, 30(7): 3031-3039.

[12] C J Zhou, L J Pan, J Xu, et al. Non-Newtonian thermal elastohydrodynamic lubrication in point contact for a crowned herringbone gear drive. Tribo/ogy International, 2017, 116: 470-481.

[13] W J Qin, J Chao, L J Duan. Study on stiffness of elastohydrodynamic line contact. Mechanism and Machine Theory, 2015, 86: 36-47.

[14] Y Y Zhang, H J Liu, C C Zhu, et al. Influence of lubrication starvation and surface waviness on the oil film stiffness of elastohydrodynamic lubrication line contact. Journal of Vibration and Control, 2018, 24(5): 924-936.

[15] S S Li, J Shao, F Yu, et al. Research on modeling method for oil-film stiffness calculation of point contact based on EHL. Advanced Materials Research, 2014: 945-949.

[16] C J Zhou, Z L Xiao, S Y Chen, et al. Normal and tangential oil film stiffness of modified spur gear with non-Newtonian elastohydro -dynamic lubrication. Tribology International, 2017, 109: 319-327.

[17] C J Zhou, Z L Xiao. Stiffness and damping models for the oil film in line contact elastohydrodynamic lubrication and applications in the gear drive. Applied Mathematical Modelling, 2018, 61: 634-649.

[18] X L Liu, P R Yang. Analysis of the thermal elastohydrodynamic lubrication of a finite line contact. Tribology International, 2002, 35: 137-144.

[19] P Yang, P R Yang. Analysis on the thermal elastohydrodynamic lubrication of tapered rollers in opposite orientation. Tribology International, 2007, 40: 1627-1637. 
[20] XJ Shi, W Sun, XQ Lu, et al. Three-dimensional mixed lubrication analysis of spur gears with machined roughness. Tribology International, 2019, 140: 105864

[21] THe, D Zhu, C J Yu, et al. Mixed elastohydrodynamic lubrication model for finite roller-coated half space interfaces. Tribology International, 2019, 134: 178-189.

[22] C L Lei, F H Li, J F Guo, et al. Analysis on the oil film stiffness of rolling bearings based on multi parameter coupling. Journal of Vibration and Shock, 2018, 37(10): 225-232

[23] X B Huang, B T Yang, Y Q Wang. A nano-lubrication solution for highspeed heavy-loaded spur gears and stiffness modelling. Applied Mathematical Modeling, 2019, 72: 623-649.

[24] Z L Xiao, X Shi. Investigation on stiffness and damping of transient non-Newtonian thermal elastohydrodynamic point contact for crowned herringbone gears. Tribology International, 2019, 137: 102 -112.

[25] J H Xue. The analysis on thermal behavior and the modification design of the high-speed and heavy-power gear system. Beijing: University of Science and Technology Beijing, 2015.

[26] G H Zhang, H B Xu, H Long. The double involute gear with ladder shape of tooth. International Gearing Conference, England, 1994.

[27] G H Zhang, H B Xu, H Long. Graded double involute gear. Journal of Mechanical Engineering, 1995, 31(6): 47-52. (in Chinese)

[28] Z M Fan. The profile parameters optimum and experiment investigation on strength property of double involute gear with ladder-shaped teeth. Chongqing: Chongqing University, 1998. (in Chinese)

[29] Z M Fan, G H Zhang. Analysis on meshing characters of double involute gear with ladder shape teeth. Journal of Mechanical Engineering, 2002, 38(9): 73-76. (in Chinese)
[30] Z M Fan, W F Zhou, R X Wang, et al. Effect of tooth waist order parameters of double involute gears on lubrication performance of gear drive. Industrial Lubrication and Tribology, 2016, 68(6): 671 -675.

[31] Z M Yin, Z M Fan, M K Wang. Thermal elastohydrodynamic lubrication characteristics of double involute gears at the graded position of tooth waist. Tribology International, 2020, (144): 106028.

[32] M H Yin. Study on dynamic of herringbone gear-rotor-journal bearing system with lubrication effects. Xi'an: Northwestern Polytechnical University, 2017.

[33] P Yang, S Z Wen. A generalized Reynolds equation for non-Newtonian thermal elastohydrodynamic lubrication. ASME Journal of Tribology, 1990, 112: 631-636.

[34] Y Huan, P R Yang. The influence of spinning on thermal EHL in elliptical contacts. Tribology, 2009, (6): 616-617.

[35] CJA Roelands, J C Vlugter, H I Waterman. The viscosity temperature pressure relationship of lubricating oils and its correlation with chemical constitution. J. Basic Eng., 1963, 85(4): 601-607.

[36] Z L Xiao, C J Zhou, Z D Li, et al. Thermo-mechanical characteristics of high-speed and heavy-load modified gears with elasto- hydrodynamic contacts. Tribology International, 2019, 131: 406-414.

[37] D Dowson, G R Higginson. Elastohydrodynamic lubrication, the fundamentals of roller and gear lubrication. Oxford: Pergamon Press, 1966.

[38] Z L Xiao. Oil film stiffness model and parameters analysis for modified spur gear based on elastohydrodynamic lubrication. Changsha: Changsha University, 2017. (in Chinese)

[39] H B Wang, C J Zhou, Y Y Lei, et al. An adhesive wear model for helical gears in line-contact mixed elastohydrodynamic lubrication, Wear, 2019, 426-427: 896-909.

\section{Submit your manuscript to a SpringerOpen ${ }^{\odot}$ journal and benefit from:}

- Convenient online submission

$\checkmark$ Rigorous peer review

- Open access: articles freely available online

- High visibility within the field

Retaining the copyright to your article

Submit your next manuscript at $\boldsymbol{\nabla}$ springeropen.com 